\title{
Dendritic cell-based vaccine prolongs survival and time to next therapy independently of the vaccine cell number
}

Simon Hawlina ${ }^{1,2+}$, Helena H. Chowdhury ${ }^{3,4 \dagger}$, Tomaž Smrkolj ${ }^{1,2}$ and Robert Zorec ${ }^{3,4^{*}}$

\begin{abstract}
In 2009, new EU legislation regulating advanced therapy medicinal products (ATMPs), consisting of gene therapy, tissue engineering and cell-based medicines, was introduced. Although less than 20 ATMPs were authorized since that time, the awarding of the Nobel Prize for Physiology or Medicine in 2018 revived interest in developing new cancer immunotherapies involving significant manipulation of the patient's own immune cells, including lymphocytes and dendritic cells. The lymphocytes are mainly thought to directly affect tumour cells, dendritic cells are involved in indirect mechanisms by antigen presentation to other leukocytes orchestrating the immune response. It is the latter cells that are the focus of this brief review. Based on the recent results of our study treating patients with castrationresistant prostate cancer (CRPC) with an immunohybridoma cell construct (termed aHyC), produced by electrofusion of autologous tumour and dendritic cells, we compare their effectiveness with a matched documented control group of patients. The results revealed that cancer-specific survival and the time to next in-line therapy (TTNT) were both significantly prolonged versus controls. When patients were observed for longer periods since the time of diagnosis of CRPC, $20 \%$ of patients had not yet progressed to the next in-line therapy even though the time under observation was $~ 80$ months. Interestingly, analysis of survival of patients revealed that the effectiveness of treatment was independent of the number of cells in the vaccine used for treatment. It is concluded that autologous dendritic cell-based immunotherapy is a new possibility to treat not only CRPC but also other solid tumours.
\end{abstract}

Keywords: Dendritic-tumor hybridoma vaccine, Autologous cell therapy, Immunotherapy, Castration-resistant prostate cancer

\section{Background}

When the EU regulation for advanced therapy medicinal products (ATMPs), consisting of gene therapy medicinal products, tissue-engineered products and cell therapy medicinal products (CTMPs), was introduced in 2009, this was considered to facilitate the innovation of better

\footnotetext{
*Correspondence: robert.zorec@mf.uni-lj.si

†Simon Hawlina and Helena H. Chowdhury have contributed equally to this work

${ }^{4}$ Laboratory of Neuroendocrinology - Molecular Cell Physiology, Institute of Pathophysiology, Faculty of Medicine, University of Ljubljana, Zaloska 4, 1000 Ljubljana, Slovenia

Full list of author information is available at the end of the article
}

medicines, offering potential treatment opportunities for diseases that currently have limited or no effective therapeutic options. Although ATMPs have gained considerable interest in the last decade or so, this has been associated with new challenges, mainly how to consider regulatory approaches that have been adopted in the past through the development of small-molecule-based medicines [1]. This is particularly relevant to using somatic cells, exposing them to substantial manipulation ex vivo and then returning them into the patient for treatment. Discussions pertinent to the use of CTMPs have frequently revisited the question whether the effectiveness of these therapies depends on the quantity of cells 
(cell dose); for example, whether a single dose of cells or repetitive administration of cells is needed, highlighting the fact that the mechanisms of action of these cells are mostly unknown, at least in the case of treating heart failure with stem cells [2]. Moreover, this question is also relevant for understanding of how cell-based medicines act in cancer cell-based immunotherapy, which is based on the power and specificity of the immune cells for the treatment of malignancy [3].

The immune system has a potential capability to recognize and attack cancer cells through the process of "immuno-editing", including elimination, equilibrium, and escape phases [4]. Tumour cells may escape immune recognition using several mechanisms that are usually associated with a protective function of healthy tissues from autoimmune interactions. These consist of inefficient processing and presentation of tumour antigens, upregulation of negative costimulatory ligands that mediate $T$ cell anergy [5], expansion of regulatory cells, and production of "immunosuppressive molecules", including Fas ligand [6], transforming growth factor $\beta$ [7] and the potentially reversible immunosuppressive enzyme indolamine-2,3-dioxygenase [8,9]. In addition, tumour cells can directly escape $\mathrm{T}$ cell recognition through downregulating major histocompatibility complex (MHC) class I or disabling other components of antigen presentation [10]. To combat cancer by cell-based-therapies, the intrinsic capacity of dendritic cells (DCs) to augment antitumor immune effector cells, such as tumour antigen-specific cytotoxic $\mathrm{T}$ lymphocytes and natural killer (NK) cells, can be harnessed [11].

In this article, we first review how DCs have been used to treat prostate cancer. Then, we focus on the recently conducted clinical trial involving cell-based immunotherapy of castration-resistant prostate cancer (CRPC) [12], in which autologous immunohybridomas (aHyC), produced by electrofusion of the patient's own tumour and DCs, were used [13, 14]. Previously, these immunohybridomas were shown to augment the cytotoxic immune cell capacity in vitro [15], a mechanism playing a role in the cell-based therapy of cancer. We then compare cancer-specific survival (CSS) and time to next in-line therapy (TTNT) of patients treated with the DC-based vaccine $(\mathrm{aHyC})$ in a recent clinical trial [12] with patients in a documented control group. Finally, we consider the question of the cell dose by comparing the CSS and TTNT of patients with CRPC with the number of cells used in the vaccine.

\section{Prostate cancer, immunotherapy and dendritic cells}

Prostate cancer (PCa), a common malignancy in men [16], can advance to the incurable CRPC. Not long ago, docetaxel chemotherapy was the only effective treatment for CRPC $[17,18]$. After the approval of several new treatments, including the alpha emitter radium-223 [19], second-line taxane cabazitaxel $[20,21]$, and the cellbased vaccine sipuleucel-T [22], patient survival was shown to be improved by up to 7 months [23-26]. On the basis of five phase 3 clinical trials (COU-AA-302, PREVAIL, PROSPER, SPARTAN and ARAMIS), in which improvements in metastasis-free survival and patient survival were shown, new androgen inhibitors, abiraterone acetate, enzalutamide, apalutamid, and darolutamid [27-31] were used. Figure 1 depicts the time course of CRPC and the time points of various therapies, standard and recently introduced. Table 1 presents data on the known mechanisms, efficacy, and toxicity of individual therapies, both currently approved and new immunotherapy for the treatment of CRPC.

Advances in cancer immunotherapy and especially the awarding of the Nobel Prize for Physiology or Medicine in 2018 to J.P. Allison and T. Honjo "for their discovery of cancer therapy by inhibition of negative immune regulation", have facilitated interest in PCa immunotherapy. However, as seen in Table 1, ipilimumab, an immunecheckpoint blocker failed to demonstrate survival benefit in patients with CRPC [32] and pembrolizumab was approved by the US Food and Drug Administration for all mismatch repair-deficient cancers or those with unstable microsatellite status, which is a rare finding in $\mathrm{PCa}$ [33]; hence, sipuleucel-T appears to be the only approved immunotherapy for CRPC [22]. The proposed mechanism of action of sipuleucel- $\mathrm{T}$, a cell-based vaccine, is induction of antigen-specific immune responses against prostatic acid phosphatase on PCa cells [34].

In previous immunotherapy clinical trials of prostate cancer treatment, several arrangements were used to address antigen presentation, ranging from a completely general strategy (most feasible in terms of vaccine production), where one antigen was used to modulate the immune system in all patients, to others with more individualized approaches (more complex and less feasible in terms of production). The general, one-for-all approach was used in the PROSTVAC trial, a viral vector-based immunotherapy consisting of recombinant poxviruses expressing prostate-specific antigen (PSA), together with three immune-enhancing costimulatory molecules, aiming to induce PSA-specific T cell responses, eventually killing PSA-expressing tumour cells [35]. The GVAX-PCa trial used a vaccine consisting of a mixture of two irradiated prostate cancer cell lines, LNCaP and PC-3, with a constitutively expressed granulocyte-macrophage colony-stimulating factor (GM-CSF), an immune cell activator [36]. In the PROSTVAC and GVAX trials, in which the vaccine was administered subcutaneously/intradermally, these treatments tended to improve median overall 


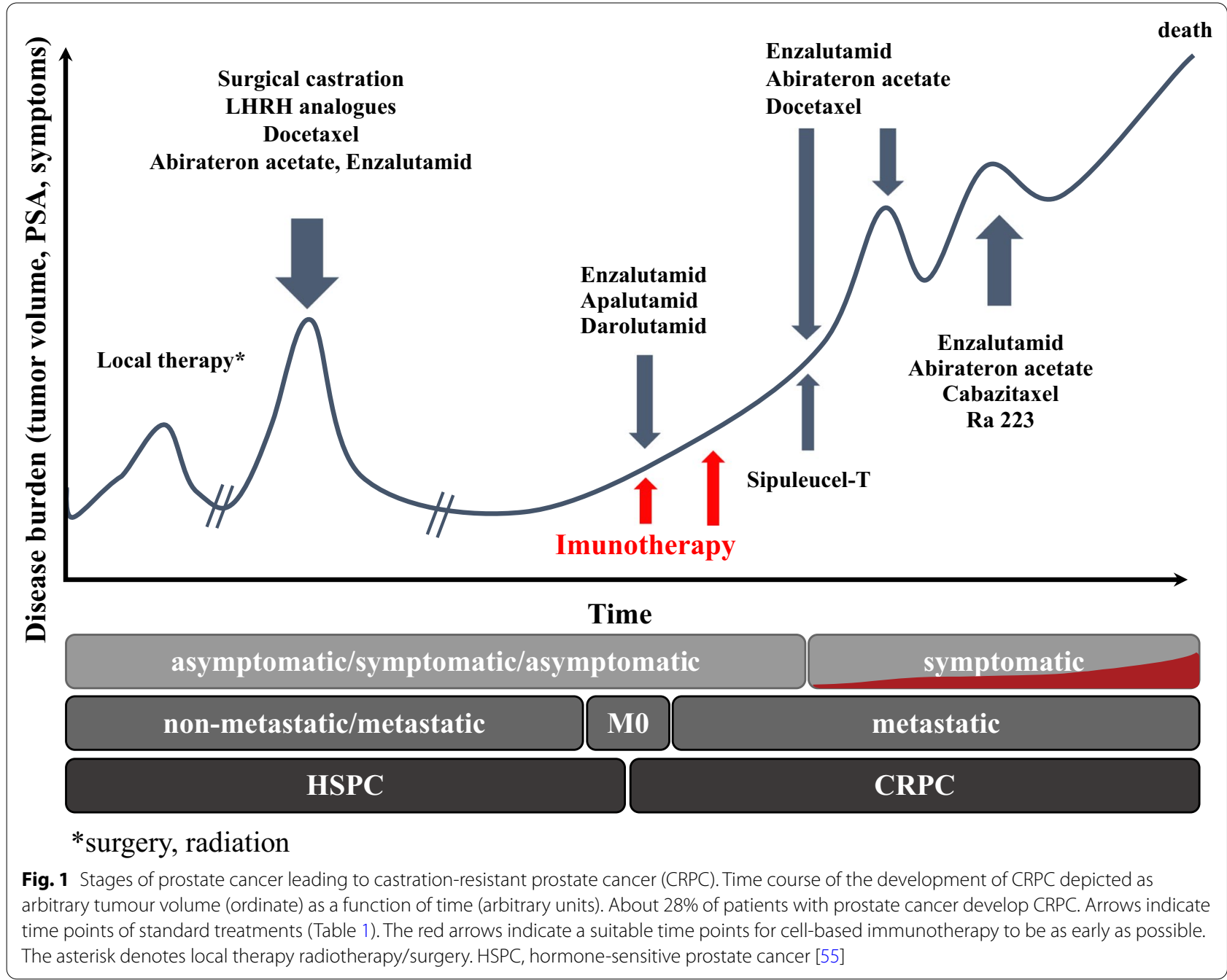

survival [24]. As most prostate cancer cells express prostatic acidic phosphatase (PAP) [37], this has been used to incubate the patient's isolated cells on an autologous basis to produce sipuleucel-T [22], which is more production intensive than the approaches mentioned earlier. Briefly, antigen-presenting cells extracted from autologous peripheral blood mononuclear cells were activated ex vivo with a recombinant fusion protein (PA2024) consisting of PAP fused to GM-CSF. The processed cells were then infused into the patient, resulting in a 4.1-month improvement in median survival, however with more side effects than in patients receiving placebo [22]. However, it is unclear whether sipuleucel- $T$ acts via priming of naive $T$ cells through antigen-presenting DCs, because it consists of less than $20 \%$ of DC markers [38].

DCs are able to activate both naive and memory $\mathrm{T}$ cells and appear an ideal target for augmenting antitumor immune responses [39]. Thus, vaccination with enriched, activated DCs may be a more potent immunotherapy strategy than the afore-mentioned approaches. Consistent with this, vaccination by blood-derived DCs, stimulated with protamine/mRNA and loaded with three tumour-associated antigens (NY-ESO-1, MAGE-C2 and MUC) resulted in more frequent detection of tetramer/ dextramer-positive $\left(\mathrm{dm}^{+}\right)$and interferon-gamma (IFN$\gamma)$-producing antigen-specific $\mathrm{T}$ cells in skin biopsy samples of patients with radiologic non-progressive disease versus patients with CRPC with progressive disease; the overall median radiologic progression-free survival was 9.5 months [40].

Instead of selecting one [22] or a few [40] effective tumour antigens that may elicit sufficient immunologic response in DC-based vaccines to treat patients with CPRC, whole tumour cells were used as the source of tumour antigens. This was achieved by electrofusing tumour and DCs to produce hybridomas, an approach 


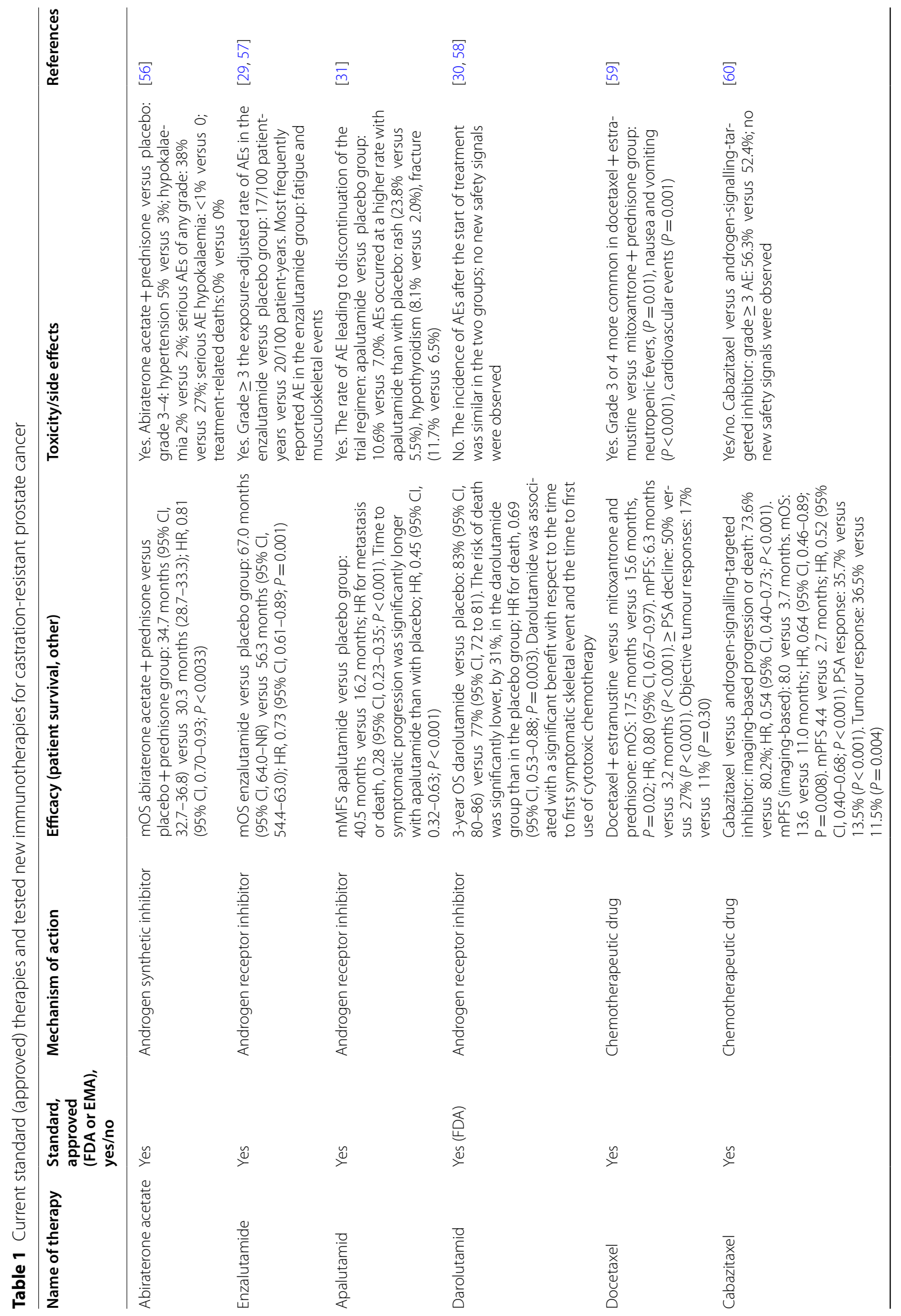




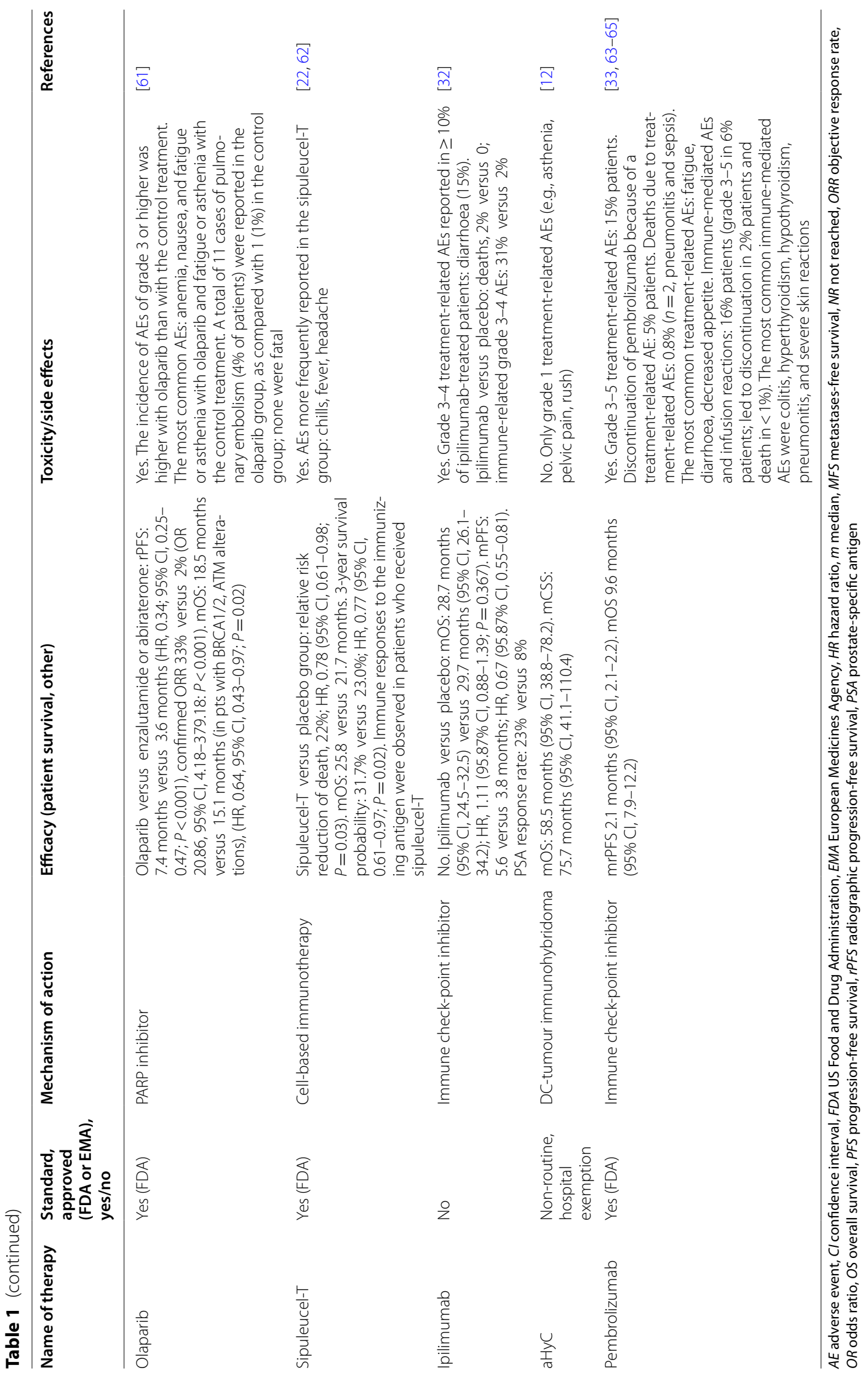


developed previously and evaluated by confocal microscopy and flow cytometry [13]. Antigen presentation involves late endocytic compartments, containing MHC class II molecules, therefore heterotypic vesicle fusion is needed to deliver antigens to MHC class II molecules in hybridomas. It was shown that fusion of late endocytic compartments also takes place in hybridomas and that the efficiency of this approach, measured as an enhanced in vitro cytotoxic $\mathrm{T}$ cell response, is stronger if a higher percentage of fused late endocytic compartments is present in the cell population of electrofused hybridoma cells $[14,15]$. The advantage of such hybridomas over other forms of DC vaccines [41] is their presentation capacity of both known and yet unknown tumour-associated antigens to $\mathrm{T}$ lymphocytes and other immune cells.

Recently, these completely autologous dendritictumour immunohybridoma cells, termed aHyC, produced as described [13], were used to treat chemotherapy-naive patients with CRPC in a phase $1 / 2$, double-blind, cross-over clinical trial [12]. The procedure for treating patients with $\mathrm{CPRC}$ with aHyC, from performing the biopsy, harvesting monocytes by leukapheresis, then using electrofusion to generate immunohybridomas and using subcutaneous injection of the cell suspension, is shown in Fig. 2. This trial tested the feasibility, assessed the safety and quality of life and evaluated clinical and immunological outcomes and overall survival (OS), with a median OS of 58.8 months [12]. Monitoring several leukocyte populations before and after vaccination, the results revealed that survival of patients with CRPC was inversely correlated with changes in peripheral blood CD56 bright $\mathrm{CD}^{-} 6^{-}$natural killer (NK) cells [12]. These cells are considered immunoregulatory cytokineproducing cells, which on appropriate activation (proinflammatory cytokines IL-2 and IL-15), can become cytotoxic [42]. In peripheral blood, $\mathrm{CD} 56^{\text {bright }} \mathrm{CD} 16^{-}$ NK cells represent a small fraction (typically around $10 \%)$ of all NK cells [43]. An increase in the fraction of $\mathrm{CD} 56^{\text {bright }} \mathrm{CD} 16^{-} \mathrm{NK}$ cells was observed in the placebo and aHyC arms. However, in the aHyC-first application

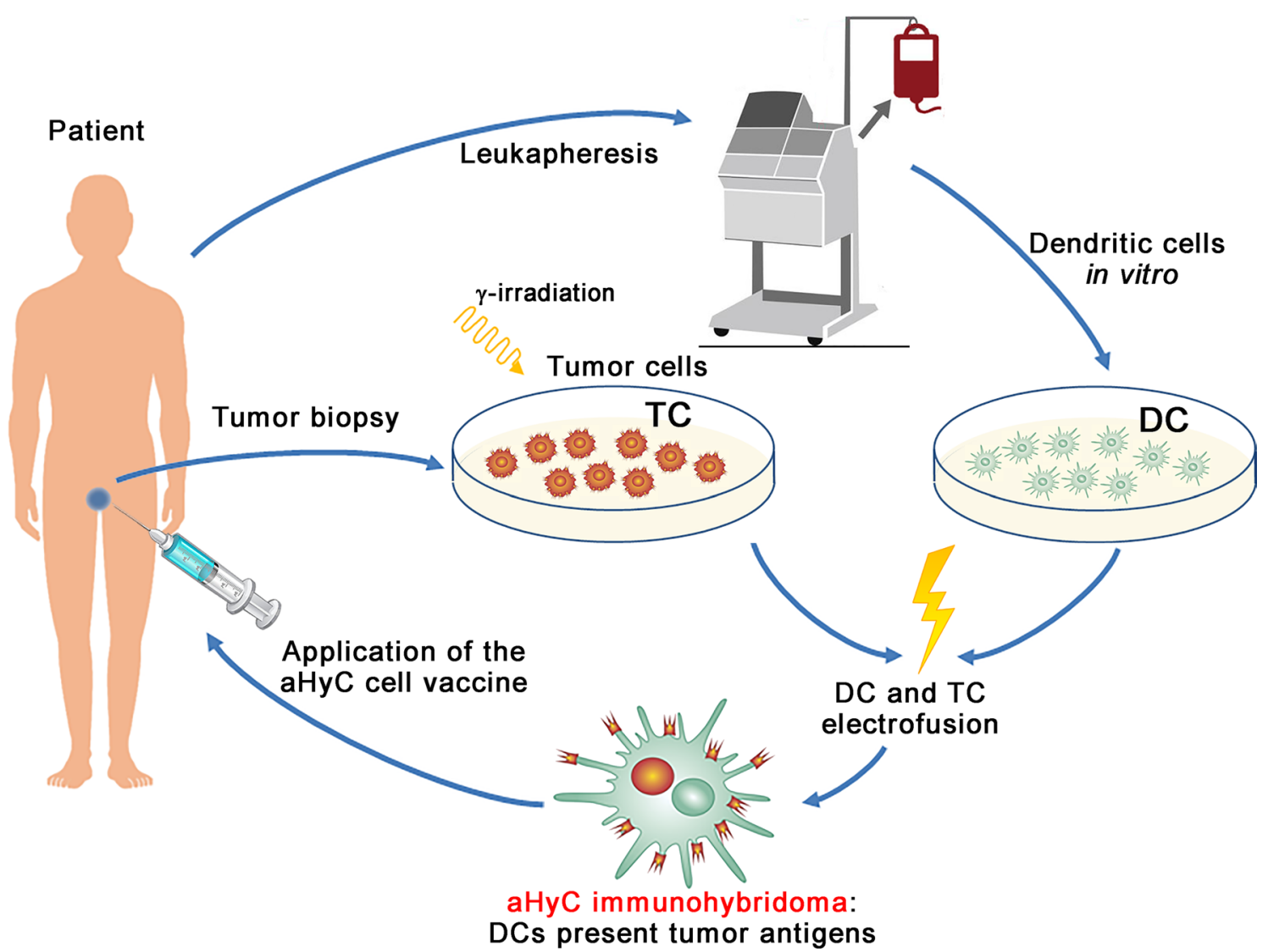

Fig. 2 The procedures used in the clinical trial treating castration-resistant prostate cancer (CRPC) [12]. Biopsy samples of the prostate were taken and a suspension of tumour cells (TC) was produced in the GMP facility. Monocytes were harvested from the same patient by leukapheresis to produce dendritic cells (DC) in the lab. These were then electrofused with TCs to obtain immunohybridomas, aHyC, which were applied subcutaneously into the patient four times 
group, this increase was significantly reduced, indicating that this may contribute to the beneficial clinical outcome recorded [12], because these regulatory NK cells may contribute to a mechanism by which tumours can evade the host immune response [44, 45]. Consistent with this in advanced malignancies, such as melanoma and breast cancer, an increase in the fraction of these cells was found to be associated with a prometastatic function of peripheral blood CD56 ${ }^{\text {bright }} \mathrm{CD} 16^{-}$NK cells $[46,47]$. However, because only a few studies addressed changes in a circulating $\mathrm{CD} 56^{\text {bright }} \mathrm{CD} 16^{-} \mathrm{NK}$ cell population in cancerous conditions previously [46-52], this needs to be readdressed in the future. The IMPACT trial (sipuleucel-T) has been subject to criticisms [53], including that there was no change in progression-free survival, no significant impacts on PSA, tumour burden, symptoms, or pain. Without a meaningful impact on surrogate endpoints, it is hard to understand and explain the observed improvement in OS. In addition, it would be beneficial to identify a marker in peripheral blood that can predictably inform clinicians and patients about the efficacy of the vaccine after treatment. Interestingly, changes in the percentage of peripheral blood $\mathrm{CD} 56^{\text {bright }} \mathrm{CD} 16^{-} \mathrm{NK}$ cell population could be a biomarker for monitoring the effectiveness of the treatment, predicting the prognosis and adjusting the therapy as soon as possible if necessary.

To further verify the effectiveness of aHyC therapy in the treatment of patients with CRPC [12], we asked whether the TTNT is altered and whether the efficacy of aHyC treatment depends on the dose of cells used in the vaccine.

\section{Prolongation of survival and TTNT in patients with CRPC treated with aHyC}

To learn whether the application of aHyC affected the clinical outcome of patients, we determined the CSS and TTNT (Fig. 1), both measures of effectiveness of aHyC treatment. We compared these parameters in relation to a matched control group of patients who did not receive aHyC (Table 2). To compare these parameters in both groups, both CSS and TTNT were determined in months from the time of diagnosis of CRPC to the cut-off date (30 September 2021) or the patient's death. We included all patients who received aHyC vaccine $(\mathrm{aHyC}$ group,

Table 2 Patient characteristics in the aHyC group (all patients who received aHyC) and in the documented control group

\begin{tabular}{|c|c|c|}
\hline & aHyC treatment group & Documented control group \\
\hline Number of patients & 19 & 21 \\
\hline Age (years) at CRPC diagnosis, median (IQR) & $74(69-81)$ & $72(69-75)$ \\
\hline Follow-up (months), median (IQR) & $65(35-81)$ & $50(41-59)$ \\
\hline Deaths, $n(\%)$ & $11(58)$ & $19(90)$ \\
\hline \multicolumn{3}{|l|}{ PSA at CRPC diagnosis, ng/mL } \\
\hline Median (IQR) & $7(4-14)$ & $11(6-14)$ \\
\hline Mean \pm SEM & $14 \pm 6$ & $13 \pm 3$ \\
\hline \multicolumn{3}{|l|}{ Gleason score, $n(\%)$} \\
\hline $8-10$ & $16(84)$ & $12(57)$ \\
\hline $6-7$ & $3(16)$ & $9(43)$ \\
\hline Median (IQR) & $9(9-9)$ & $8(7-9)$ \\
\hline \multicolumn{3}{|l|}{ Metastases at CRPC* $n(\%)$} \\
\hline No metastases & $12(63)$ & $15(71)$ \\
\hline Oligometastases $(\leq 3)$ & $3(21)$ & $6(29)$ \\
\hline Polymetastases $(\geq 4)$ & $4(16)$ & 0 \\
\hline \multicolumn{3}{|l|}{ Site of metastases*, n (\%) } \\
\hline Bone & $4(21)$ & $4(19)$ \\
\hline Lymph node & 0 & $2(10)$ \\
\hline Bone + lymph node & $3(16)$ & 0 \\
\hline Visceral & 0 & 0 \\
\hline \multicolumn{3}{|c|}{ Next-in-line treatment (docetaxel, enzalutamide, abiraterone acetate) up to 30 September 2021} \\
\hline Yes, n (\%) & $13(68)$ & $21(100)$ \\
\hline TTNT (months), median (HR; 95\% Cl) & $28(0.31 ; 0.15-0.63)$ & $16(3.25 ; 1.59-6.64)$ \\
\hline
\end{tabular}

aHyC autologous hybridoma cell, $C I$ confidence interval, CRPC castration-resistant prostate cancer, HR hazard ratio, IQR interquartile range, $P S A$ prostate-specific antigen, TTNT time to next therapy

${ }^{*}$ Metastases were determined with routinely performed nuclear medicine bone scan and computed tomography of thorax and abdomen or ${ }^{18} \mathrm{~F}$ choline positron emission tomography-computed tomography 
$n=19)$ and a control group $(n=21)$. At the cut-off date, the incidence of any cause of death was $58 \%$ (11 patients) within the aHyC group and 90\% (19 patients) in the documented control group. Both groups were comparable for age at CRPC diagnosis (74 and 72 years) and other characteristics (Table 2).

From the time of diagnosis of CRPC, CSS was prolonged by 32.7 months $(P<0.05)$ in patients who received aHyC (82.2 months) compared with patients in the documented control group who did not receive aHyC (49.5 months; Fig. 3A). In patients with non-metastatic CRPC (M0; Fig. 3B) who received aHyC (note that the median value is not reached), CSS was much longer $(P=0.03)$ than in patients in the documented control group who did not receive aHyC (48.3 months). The considerably prolonged CSS in MO aHyC-treated patients compared with CSS recorded in all, metastatic (M1) and M0 patients treated with aHyC (Fig. 3A) clearly suggests that prostate cancer vaccines may be more beneficial when given early, at the stage of $\mathrm{M} 0$, because the immune system has time to mount a response, the disease burden is low and before immune system evasion by the tumour [54]. Moreover, it is likely that sourcing tumour antigens by biopsy from the prostate is relatively complete in non-metastatic disease, whereas in metastatic patients, tumour antigens in the metastases differ significantly from tumour antigens in the primary tumour in the prostate, and thus in the vaccine. These results indicate that patients with non-metastatic CRPC will benefit best from treating with immunotherapy aHyC.
Interestingly, TTNT was determined as the time from CRPC diagnosis to the beginning of the next in-line standard treatment (i.e., docetaxel, abiraterone acetate, enzalutamide; Fig. 1) or to the cut-off date in both groups. The same criteria were used for the introduction of the next in-line treatment in patients in the aHyC group and in the control group (Table 2). The median TTNT in the aHyC group was 12.1 months longer (28.0 months, hazard ratio, 0.31 (95\% confidence interval, $0.15-0.63) ; P<0.001)$ than that in the control group (15.9 months; Fig. 4). Overall, these results indicate that $\mathrm{aHyC}$ treatment is beneficial for patients by prolonging CSS and TTNT. To better understand the mechanism of this process, we looked next at the cell number in the vaccine used to treat patients.

\section{Independent relationship between survival or TTNT and the cell number in the vaccine}

In a recent clinical study, it was revealed that the survival of patients with CRPC was negatively correlated with the change in the percentage of the peripheral blood CD56 ${ }^{\text {bright }} \mathrm{CD} 16^{-} \mathrm{NK}$ cell population [12]. This indicates that subcutaneous injection of the aHyC cell vaccine induced an immune response, measured as a reduction in the subpopulation of NK cells. This raises the question of how this measured change was linked to the DC-based vaccination by aHyC? One way to address this issue is to determine whether the immune response and the survival or TTNT depended on the number of cells in the vaccine. Given that the amount of cells harvested in the

\section{A}

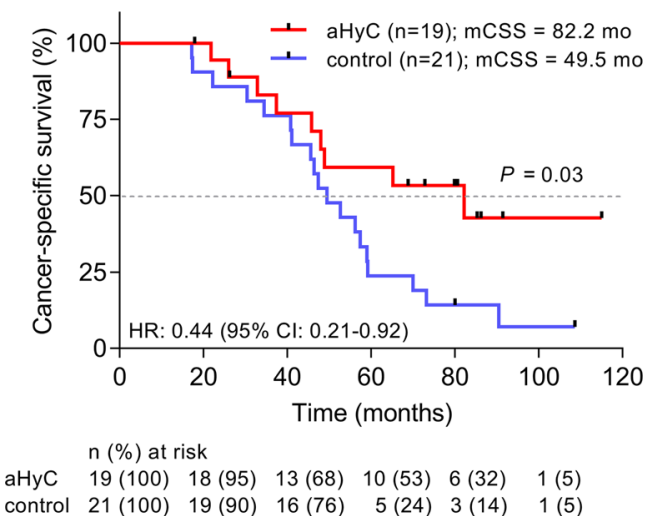

\section{B Cancer-specific survival of M0 patients}

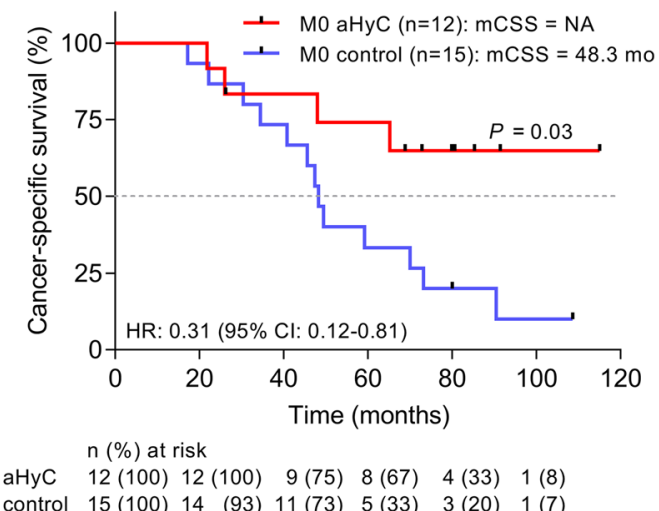

Fig. 3 Cancer-specific survival (CSS). A CSS after diagnosis of castration-resistant prostate cancer (CRPC) was significantly prolonged ( $P=0.03)$ by 32.7 months in patients who received aHyC (red, 82.2 months) compared with patients in the documented control group who did not receive aHyC (blue, 49.5 months). B CSS was further compared only in patients with non-metastatic (M0) CRPC. Median CSS survival was not reached in patients who received aHyC (red line), and it was significantly shorter $(P=0.03$ ) in patients in the documented control group who did not receive aHyC (blue line, 48.3 months). Black dots on the lines represent censored events of specific survival. The common starting point for both groups of patients was the diagnosis of CRPC; cut-off date was 30 September 2021. The tables below the graphs show the number and proportion of patients in both groups who are still at risk at individual time points on the graphs. NA, median value not yet reached; MO, non-metastatic CRPC 


\section{Time to next treatment (TTNT)}

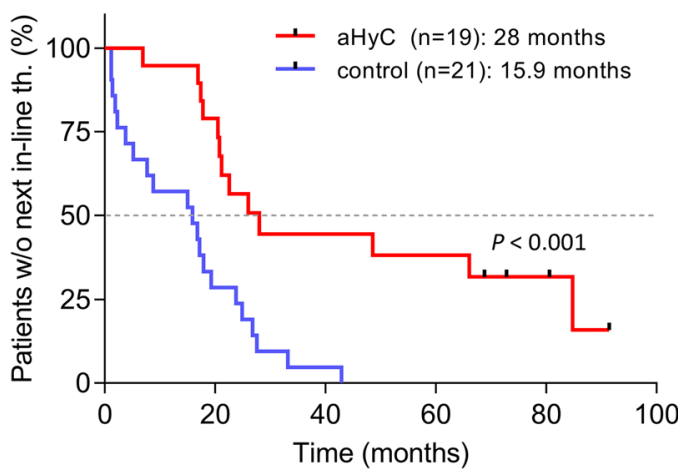

n (\%) at risk

$$
\text { aHyC } 19(100) \quad 14(74) \quad 7(37) \quad 6(32) \quad 3(16)
$$$$
\text { control } 21(100) \quad 6(29) \quad 1(5) \quad 0 \quad 0
$$

Fig. 4 Time to next therapy (TTNT) from the time of diagnosis of castration-resistant prostate cancer (CRPC). The ordinate denotes the percentage of patients without next in-line therapy. The red curve represents patients who received aHyC therapy; the median TTNT (mTTNT) was 28 months, significantly longer $(P<0.001)$ than the time recorded in control patients (blue curve; 15.9 months), yielding a prolongation of 12.1 months without the need for the next in-line therapy by the aHyC application. In both groups, TTNT was determined by taking into account the time of CRPC diagnosis; data were analysed considering the cut-off date 30 September 2021. Black marks on the red curve indicate censored events (patients who did not receive the next in-line therapy). The table below the plot indicates the number and percentage of patients in both groups who have not yet received any next in-line standard therapy at time points in months on the plot prostate biopsies varied between patients [12], we asked whether the number of cells in the aHyC vaccine was related to the survival of patients. Figure $5 \mathrm{~A}$ shows the relationship between the survival of patients as a function of the number of cells in the vaccination procedure. The Pearson correlation coefficient $r$ is -0.14 . A similar non-significant $r$ of 0.36 was found in the relationship between the TTNT and the number of cells in the vaccination treatment (Fig. 5B). One would expect that better survival or longer TTNT would be related to the cell dose, because this is expected in dose-dependent studies using small-molecule medicines. However, in cellbased therapy, especially when DCs are used to generate antigen presentation, perhaps a low number of cells or even just one is needed to generate a threshold-dependent effect in antigen presentation and indirectly affect tumour cells. This will have to be investigated further in the future.

\section{Conclusions}

DCs have been used in clinical trials as a form of therapeutic vaccination of patients with cancer for over three decades, demonstrating that this approach is safe and can induce antitumor immunity. However, the clinical responses have been disappointing, because not all studies were designed primarily to measure survival [11]. As presented in this brief review, this has improved.

A recent study treating patients with CRPC revealed that survival of patients was negatively correlated

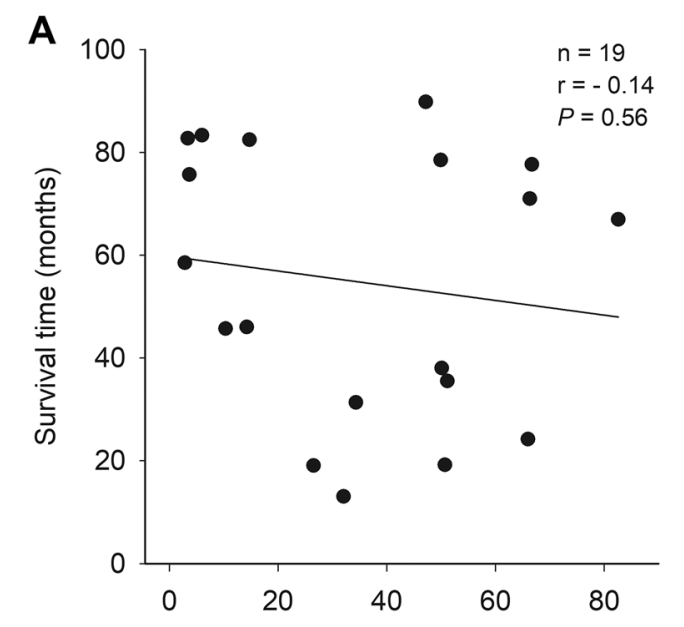

$\mathrm{N}$ of viable cells in all four vaccines $\left(\times 10^{6}\right)$

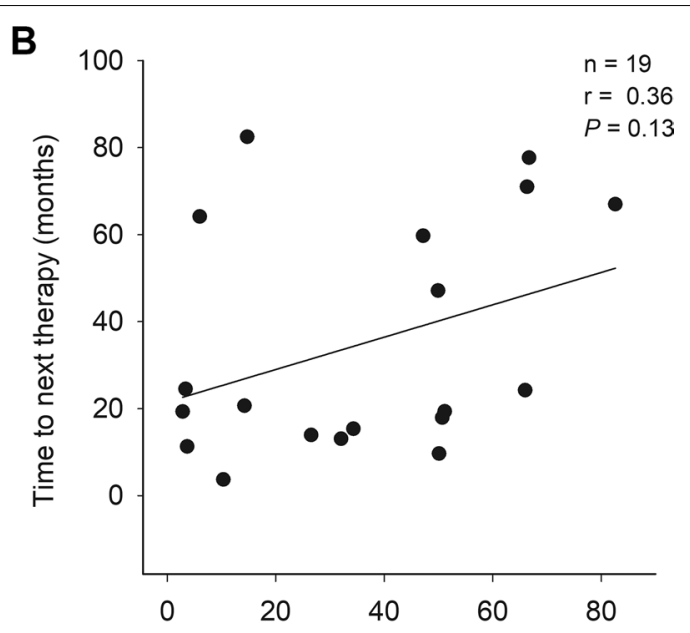

$\mathrm{N}$ of viable cells in all four vaccines $\left(\times 10^{6}\right)$

Fig. 5 Independence of survival and time to next therapy (TTNT) from the number of cells in vaccines. A The ordinate denotes the survival of patients with castration-resistant prostate cancer (CRPC) treated with aHyC and the abscissa shows the number of cells in the vaccination procedure in each of the patients. Survival was determined from the time of first application (aHyC or placebo) until death or the cut-off date (30 September 2021). B The ordinate denotes the time (in months) to TTNT from the start of the clinical trial and the abscissa shows the number of cells in the vaccination procedure for each of the 19 patients. TTNT was determined from the time of first application (aHyC or placebo) until the next in-line therapy or the cut-off date (30 September 2021). Pearson correlation coefficients $(r)$ show that there is no significant relationship between the survival of patients with CRPC or TTNT and the number of cells in the vaccines 
to a subpopulation of NK cells [12], indicating that DC-based vaccines engage NK cells in the immune response, as considered previously [11]. Moreover, we show the relationship between survival and the dose of cells in the vaccine (Fig. 5). These data are important not only for understanding the mechanism of action of DC cell-based immunotherapy but also in view of the legislation and rules dealing with ATMPs, a key challenge in implementing regulatory approaches that have been adopted in the past through the development of small-molecule-based medicines [1]. For example, to validate the safety of new small-molecule-based medicines, it is imperative to carry out dose-escalation studies, but in cell-based advanced immunotherapy products, the mechanism of action may not be as simple as the interaction between a small molecule and its receptor. Here, we show that survival or TTNT is independent of the number of cells in the vaccine, pointing to the possibility that, in the case of DC-based vaccines, a minimal threshold number of cells is needed to elicit a treatment-related immune response. Therefore, this needs to be taken into account in preparing DCtumour immunohybridoma vaccines in future clinical trial designs.

\begin{abstract}
Abbreviations
AE: Adverse event; aHyC: Autologous hybridoma cell; ATMP: Advanced therapy medicinal products; Cl: Confidence interval; CRPC: Castration-resistant prostate cancer; CSS: Cancer-specific survival; CTMP: Cell therapy medicinal products; DC: Dendritic cell; EU: European Union; FDA: US Food and Drug Administration; EMA: European Medicines Agency; GM-CSF: Granulocytemacrophage colony-stimulating factor; GMP: Good manufacturing practice; HR: Hazard ratio; HSPC: Hormone-sensitive prostate cancer; IFN- $\gamma$ : Interferongamma; IL: Interleukin; IQR: Interquartile range; MO: Non-metastatic; M1: Metastatic; m: Median; MFS: Metastases-free survival; MHC: Major histocompatibility complex; NA: Not applicable; NK: Natural killer; NR: Not reached; ORR: Objective response rate; OR: Odds ratio; OS: Overall survival; PAP: Prostatic acidic phosphatase; PCa: Prostate cancer; PFS: Progression-free survival; rPFS: Radiographic progression-free survival; PSA: Prostate-specific antigen; TC: Tumour cells; TTNT: Time to next in-line therapy.
\end{abstract}

\section{Acknowledgements}

We thank the Oncology Institute Ljubljana for access to the national database of oncology patients, helping us to generate the documented group of patients with CRPC. The support of the nurses who coordinated the patients, technical assistance, and the initial work with cell cultures are acknowledged.

\section{Authors' contributions}

RZ wrote the first draft; $\mathrm{SH}$ and HHC prepared figures, HHC prepared data analysis. All authors reviewed the manuscript. All authors read and approved the final manuscript.

\section{Funding}

The authors' work was supported by grants from the Slovenian Research Agency (P3-0310, J3-6790, J3-9266, J3-2523, J3-7605, J3-062), COST Actions CM1207 (GLISTEN), BM1402 (MouseAGE) and CA15214 (EuroCellNet). We thank CipKeBip and CELSA for allowing us to use superresolution microscopy and the INTERREG Immuno-Cluster project.

\section{Availability of data and materials}

Data generated and analyzed during the current study are available from the corresponding author on reasonable request. Clinical trial protocol is available at link: http://www.Inmcp.mf.uni-lj.si/Protocol.pdf.

\section{Declarations}

\section{Ethics approval and consent to participate}

This study was conducted in accordance with the provisions of the Declaration of Helsinki and was approved in June 2013 by the National Medical Ethics Committee and the Agency for Medicinal Products and Medical Devices of the Republic of Slovenia, part of European Medical Agency (EMA). Trial EMA registration: EUDRACT: 2012-005498-29 (Register). All participants signed written informed consent prior to inclusion in the study.

\section{Consent for publication}

Not applicable.

\section{Competing interests}

The authors declare no competing interests.

\section{Author details}

${ }^{1}$ Clinical Department of Urology, University Medical Centre Ljubljana, 1000 Ljubljana, Slovenia. ${ }^{2}$ Department of Surgery, Faculty of Medicine, University of Ljubljana, 1000 Ljubljana, Slovenia. ${ }^{3}$ Laboratory of Cell Engineering, Celica Biomedical, 1000 Ljubljana, Slovenia. ${ }^{4}$ Laboratory of Neuroendocrinology Molecular Cell Physiology, Institute of Pathophysiology, Faculty of Medicine, University of Ljubljana, Zaloska 4, 1000 Ljubljana, Slovenia.

Received: 23 November 2021 Accepted: 15 December 2021

Published online: 23 February 2022

\section{References}

1. Committee for Advanced T, Secretariat CATS, Schneider CK, Salmikangas $\mathrm{P}$, Jilma B, Flamion B, et al. Challenges with advanced therapy medicinal products and how to meet them. Nat Rev Drug Discov. 2010;9(3):195-201.

2. Wysoczynski M, Khan A, Bolli R. New paradigms in cell therapy: repeated dosing, intravenous delivery, immunomodulatory actions, and new cell types. Circ Res. 2018;123(2):138-58.

3. Katz T, Avivi I, Benyamini N, Rosenblatt J, Avigan D. Dendritic cell cancer vaccines: from the bench to the bedside. Rambam Maimonides Med J. 2014;5(4):e0024.

4. Dunn GP, Old LJ, Schreiber RD. The three Es of cancer immunoediting. Annu Rev Immunol. 2004;22:329-60.

5. Yaguchi T, Sumimoto H, Kudo-Saito C, Tsukamoto N, Ueda R, I wata-Kajihara T, et al. The mechanisms of cancer immunoescape and development of overcoming strategies. Int J Hematol. 2011;93(3):294-300.

6. Houston A, Bennett MW, O'Sullivan GC, Shanahan F, O'Connell J. Fas ligand mediates immune privilege and not inflammation in human colon cancer, irrespective of TGF-beta expression. Br J Cancer. 2003;89(7):1345-51.

7. Teicher BA. Transforming growth factor-beta and the immune response to malignant disease. Clin Cancer Res. 2007;13(21):6247-51.

8. Muller AJ, Prendergast GC. Indoleamine 2,3-dioxygenase in immune suppression and cancer. Curr Cancer Drug Targets. 2007;7(1):31-40.

9. Triplett TA, Garrison KC, Marshall N, Donkor M, Blazeck J, Lamb C, et al. Reversal of indoleamine 2,3-dioxygenase-mediated cancer immune suppression by systemic kynurenine depletion with a therapeutic enzyme. Nat Biotechnol. 2018;36(8):758-64.

10. Garrido F, Ruiz-Cabello F, Cabrera T, Perez-Villar JJ, Lopez-Botet M, Duggan-Keen $\mathrm{M}$, et al. Implications for immunosurveillance of altered HLA class I phenotypes in human tumours. Immunol Today. 1997;18(2):89-95.

11. Anguille S, Smits EL, Lion E, van Tendeloo VF, Berneman ZN. Clinical use of dendritic cells for cancer therapy. Lancet Oncol. 2014;15(7):e257-67.

12. Haque Chowdhury H, Hawlina S, Gabrijel M, Trkov Bobnar S, Kreft M, Lenart G, et al. Survival of castration-resistant prostate cancer patients treated with dendritic-tumor cell hybridomas is negatively correlated 
with changes in peripheral blood $\mathrm{CD} 56^{(\text {bright) }} \mathrm{CD} 16^{(-)}$natural killer cells. Clin Transl Med. 2021;11(8):e505.

13. Gabrijel M, Repnik U, Kreft M, Grilc S, Jeras M, Zorec R. Quantification of cell hybridoma yields with confocal microscopy and flow cytometry. Biochem Biophys Res Commun. 2004;314(3):717-23.

14. Gabrijel M, Kreft M, Zorec R. Monitoring lysosomal fusion in electrofused hybridoma cells. Biochim Biophys Acta. 2008;1778(2):483-90.

15. Gabrijel M, Bergant M, Kreft M, Jeras M, Zorec R. Fused late endocytic compartments and immunostimulatory capacity of dendritic-tumor cell hybridomas. J Membr Biol. 2009;229(1):11-8.

16. Siegel RL, Miller KD, Jemal A. Cancer statistics, 2020. CA Cancer J Clin. 2020;70(1):7-30.

17. Berthold DR, Pond GR, Soban F, de Wit R, Eisenberger M, Tannock IF. Docetaxel plus prednisone or mitoxantrone plus prednisone for advanced prostate cancer: updated survival in the TAX 327 study. J Clin Oncol. 2008;26(2):242-5.

18. Tannock IF, de Wit R, Berry WR, Horti J, Pluzanska A, Chi KN, et al. Docetaxel plus prednisone or mitoxantrone plus prednisone for advanced prostate cancer. N Engl J Med. 2004;351(15):1502-12.

19. Parker C, Nilsson S, Heinrich D, Helle SI, O'Sullivan JM, Fossa SD, et al. Alpha emitter radium-223 and survival in metastatic prostate cancer. N Engl J Med. 2013;369(3):213-23.

20. Eisenberger M, Hardy-Bessard AC, Kim CS, Geczi L, Ford D, Mourey L, et al. Phase III study comparing a reduced dose of cabazitaxel $(20 \mathrm{mg} / \mathrm{m}(2))$ and the currently approved dose $(25 \mathrm{mg} / \mathrm{m}(2))$ in postdocetaxel patients with metastatic castration-resistant prostate cancer-proselica. J Clin Oncol. 2017;35(28):3198-206.

21. de Bono JS, Oudard S, Ozguroglu M, Hansen S, Machiels JP, Kocak I, et al. Prednisone plus cabazitaxel or mitoxantrone for metastatic castrationresistant prostate cancer progressing after docetaxel treatment: a randomised open-label trial. Lancet. 2010;376(9747):1147-54.

22. Kantoff PW, Higano CS, Shore ND, Berger ER, Small EJ, Penson DF, et al. Sipuleucel-T immunotherapy for castration-resistant prostate cancer. N Engl J Med. 2010;363(5):411-22.

23. DexTech. https://dextechmedical.Com/en/prostate-cancer/castrationresistant-prostate-cancer-crpc/. 2020.

24. Geary SM, Salem AK. Prostate cancer vaccines: update on clinical development. Oncoimmunology. 2013;2(5):e24523.

25. Mottet N, van den Bergh RCN, Briers E, Van den Broeck T, Cumberbatch MG, De Santis M, Fanti S, et al. Prostate cancer. https://www.uroweborg/ guideline/prostate-cancer/. 2020.

26. Francini E, Gray KP, Shaw GK, Evan CP, Hamid AA, Perry CE, et al. Impact of new systemic therapies on overall survival of patients with metastatic castration-resistant prostate cancer in a hospital-based registry. Prostate Cancer Prostatic Dis. 2019;22(3):420-7.

27. Ryan CJ, Smith MR, Fizazi K, Saad F, Mulders PF, Sternberg CN, et al. Abiraterone acetate plus prednisone versus placebo plus prednisone in chemotherapy-naive men with metastatic castration-resistant prostate cancer (COU-AA-302): final overall survival analysis of a randomised, double-blind, placebo-controlled phase 3 study. Lancet Oncol. 2015;16(2):152-60.

28. Scher HI, Fizazi K, Saad F, Taplin ME, Sternberg CN, Miller K, et al. Increased survival with enzalutamide in prostate cancer after chemotherapy. N Engl J Med. 2012;367(13):1187-97.

29. Hussain M, Fizazi K, Saad F, Rathenborg P, Shore N, Ferreira U, et al. Enzalutamide in men with nonmetastatic, castration-resistant prostate cancer. $\mathrm{N}$ Engl J Med. 2018:378(26):2465-74.

30. Fizazi K, Shore N, Tammela TL, Ulys A, Vjaters E, Polyakov S, et al. Darolutamide in nonmetastatic, castration-resistant prostate cancer. N Engl J Med. 2019;380(13):1235-46.

31. Smith MR, Saad F, Chowdhury S, Oudard S, Hadaschik BA, Graff JN, et al. Apalutamide treatment and metastasis-free survival in prostate cancer. $\mathrm{N}$ Engl J Med. 2018;378(15):1408-18.

32. Beer TM, Kwon ED, Drake CG, Fizazi K, Logothetis C, Gravis G, et al. Randomized, double-blind, phase III trial of ipilimumab versus placebo in asymptomatic or minimally symptomatic patients with metastatic chemotherapy-naive castration-resistant prostate cancer. J Clin Oncol. 2017:35(1):40-7.

33. Le DT, Uram JN, Wang H, Bartlett BR, Kemberling H, Eyring AD, et al. PD-1 blockade in tumors with mismatch-repair deficiency. $\mathrm{N}$ Engl $\mathrm{J}$ Med. 2015;372(26):2509-20.
34. Sheikh NA, Petrylak D, Kantoff PW, Dela Rosa C, Stewart FP, Kuan LY, et al. Sipuleucel-T immune parameters correlate with survival: an analysis of the randomized phase 3 clinical trials in men with castration-resistant prostate cancer. Cancer Immunol Immunother. 2013;62(1):137-47.

35. Muthana SM, Gulley JL, Hodge JW, Schlom J, Gildersleeve JC. ABO blood type correlates with survival on prostate cancer vaccine therapy. Oncotarget. 2015;6(31):32244-56.

36. Small EJ, Sacks N, Nemunaitis J, Urba WJ, Dula E, Centeno AS, et al. Granulocyte macrophage colony-stimulating factor-secreting allogeneic cellular immunotherapy for hormone-refractory prostate cancer. Clin Cancer Res. 2007;13(13):3883-91.

37. Risk M, Corman JM. The role of immunotherapy in prostate cancer: an overview of current approaches in development. Rev Urol. 2009;11(1):16-27.

38. Burch PA, Breen JK, Buckner JC, Gastineau DA, Kaur JA, Laus RL, et al. Priming tissue-specific cellular immunity in a phase I trial of autologous dendritic cells for prostate cancer. Clin Cancer Res. 2000;6(6):2175-82.

39. Koido S. Dendritic-tumor fusion cell-based cancer vaccines. Int J Mol Sci. 2016;17(6):828.

40. Westdorp H, Creemers JHA, van Oort IM, Schreibelt G, Gorris MAJ, Mehra N, et al. Blood-derived dendritic cell vaccinations induce immune responses that correlate with clinical outcome in patients with chemo-naive castration-resistant prostate cancer. J Immunother Cancer. 2019;7(1):302.

41. Rosenblatt J, Kufe D, Avigan D. Dendritic cell fusion vaccines for cancer immunotherapy. Expert Opin Biol Ther. 2005;5(5):703-15.

42. Wagner JA, Rosario M, Romee R, Berrien-Elliott MM, Schneider SE, Leong $\mathrm{JW}$, et al. CD56 bright NK cells exhibit potent antitumor responses following IL-15 priming. J Clin Investig. 2017;127(11):4042-58.

43. Michel T, Poli A, Cuapio A, Briquemont B, Iserentant G, Ollert M, et al. Human CD56 bright NK cells: an update. J Immunol. 2016;196(7):2923-31.

44. Levi I, Amsalem H, Nissan A, Darash-Yahana M, Peretz T, Mandelboim $O$, et al. Characterization of tumor infiltrating natural killer cell subset. Oncotarget. 2015;6(15):13835-43.

45. Pasero C, Gravis G, Guerin M, Granjeaud S, Thomassin-Piana J, Rocchi $P$, et al. Inherent and tumor-driven immune tolerance in the prostate microenvironment impairs natural killer cell antitumor activity. Cancer Res. 2016;76(8):2153-65.

46. Mamessier E, Pradel LC, Thibult ML, Drevet C, Zouine A, Jacquemier J, et al. Peripheral blood NK cells from breast cancer patients are tumorinduced composite subsets. J Immunol. 2013;190(5):2424-36.

47. Holtan SG, Creedon DJ, Thompson MA, Nevala WK, Markovic SN. Expansion of CD16-negative natural killer cells in the peripheral blood of patients with metastatic melanoma. Clin Dev Immunol. 2011:2011:316314.

48. Koo KC, Shim DH, Yang CM, Lee SB, Kim SM, Shin TY, et al. Reduction of the $\mathrm{CD} 16^{(-)} \mathrm{CD} 56^{\text {bright }} \mathrm{NK}$ cell subset precedes NK cell dysfunction in prostate cancer. PLoS ONE. 2013;8(11):e78049.

49. Bauernhofer T, Kuss I, Henderson B, Baum AS, Whiteside TL. Preferential apoptosis of CD56 dim natural killer cell subset in patients with cancer. Eur J Immunol. 2003;33(1):119-24.

50. Wulff S, Pries R, Borngen K, Trenkle T, Wollenberg B. Decreased levels of circulating regulatory NK cells in patients with head and neck cancer throughout all tumor stages. Anticancer Res. 2009;29(8):3053-7.

51. Kloss S, Chambron N, Gardlowski T, Arseniev L, Koch J, Esser R, et al. Increased sMICA and TGFbeta1 levels in HNSCC patients impair NKG2Ddependent functionality of activated NK cells. Oncoimmunology. 2015;4(11):e1055993.

52. Stabile H, Nisti P, Morrone S, Pagliara D, Bertaina A, Locatelli F, et al. Multifunctional human $\mathrm{CD} 56^{\text {low }} \mathrm{CD} 16^{\text {low }}$ natural killer cells are the prominent subset in bone marrow of both healthy pediatric donors and leukemic patients. Haematologica. 2015;100(4):489-98.

53. Prasad V, Berger VW. Hard-wired bias: how even double-blind, randomized controlled trials can be skewed from the start. Mayo Clin Proc. 2015;90(9):1171-5.

54. Janiczek M, Szylberg L, Kasperska A, Kowalewski A, Parol M, Antosik P, et al. Immunotherapy as a promising treatment for prostate cancer: a systematic review. J Immunol Res. 2017;2017:4861570.

55. Mao Y, Hu M, Yang G, Gao E, Chen W. Current status of castration-resistant prostate cancer drug therapy. Int J Surg Oncol. 2021;6(1):41-9. 
56. Ryan CJ, Smith MR, Fizazi K, Saad F, Mulders PF, Sternberg CN, et al. Abiraterone acetate plus prednisone versus placebo plus prednisone in chemotherapy-naive men with metastatic castration-resistant prostate cancer (COU-AA-302): final overall survival analysis of a randomised, doubleblind, placebo-controlled phase 3 study. Lancet Oncol. 2015;16:152-60.

57. Sternberg CN, Fizazi K, Saad F, Shore ND, De Giorgi U, Penson DF, et al. Enzalutamide and survival in nonmetastatic, castration-resistant prostate cancer. N Engl J Med. 2020;382(23):2197-206.

58. Fizazi K, Shore N, Tammela TL, Ulys A, Vjaters E, Polyakov S, et al. Nonmetastatic, castration-resistant prostate cancer and survival with darolutamide. N Engl J Med. 2020;383(11):1040-9.

59. Petrylak DP, Tangen CM, Hussain MH, Lara PN Jr, Jones JA, Taplin ME, et al. Docetaxel and estramustine compared with mitoxantrone and prednisone for advanced refractory prostate cancer. N Engl J Med. 2004;351(15):1513-20.

60. de Wit R, de Bono J, Sternberg CN, Fizazi K, Tombal B, Wulfing C, et al. Cabazitaxel versus abiraterone or enzalutamide in metastatic prostate cancer. N Engl J Med. 2019;381(26):2506-18.

61. de Bono J, Mateo J, Fizazi K, Saad F, Shore N, Sandhu S, et al. Olaparib for metastatic castration-resistant prostate cancer. N Engl J Med. 2020;382(22):2091-102.

62. Dores GM, Bryant-Genevier M, Perez-Vilar S. Adverse events associated with the use of sipuleucel-T reported to the US Food and Drug Administration's adverse event reporting system, 2010-2017. JAMA Netw Open. 2019;2(8):e199249.

63. Cabel L, Riva F, Servois V, Livartowski A, Daniel C, Rampanou A, et al. Circulating tumor DNA changes for early monitoring of anti-PD1 immunotherapy: a proof-of-concept study. Ann Oncol. 2017;28(8):1996-2001.

64. Fizazi K, Drake CG, Beer TM, Kwon ED, Scher HI, Gerritsen WR, et al. Final analysis of the ipilimumab versus placebo following radiotherapy phase III trial in postdocetaxel metastatic castration-resistant prostate cancer identifies an excess of long-term survivors. Eur Urol. 2020;78(6):822-30.

65. Petrylak DP, Ratta R, Gafanov R, Facchini G, Piulats JM, Kramer G, et al. KEYNOTE-921: phase III study of pembrolizumab plus docetaxel for metastatic castration-resistant prostate cancer. Future Oncol. 2021;17(25):3291-9.

\section{Publisher's Note}

Springer Nature remains neutral with regard to jurisdictional claims in published maps and institutional affiliations.

Ready to submit your research? Choose BMC and benefit from:

- fast, convenient online submission

- thorough peer review by experienced researchers in your field

- rapid publication on acceptance

- support for research data, including large and complex data types

- gold Open Access which fosters wider collaboration and increased citations

- maximum visibility for your research: over $100 \mathrm{M}$ website views per year

At BMC, research is always in progress.

Learn more biomedcentral.com/submissions 